\title{
Infliximab to treat chronic uveitis in juvenile idiopathic arthritis
} (JIA)

\author{
C Bracaglia*, PS Buonuomo, S Caminiti, A Insalaco, A Campana and E Cortis
}

Address: Division of Rheumatology, Department of Pediatric Medicine, IRCCS Ospedale Pediatrico Bambino Gesù, Rome, Italy

* Corresponding author

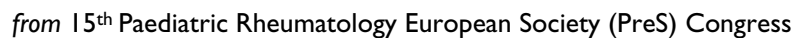

London, UK. 14-17 September 2008

Published: 15 September 2008

Pediatric Rheumatology 2008, 6(Suppl I):P47 doi:I0.I 186/I546-0096-6-SI-P47

This abstract is available from: http://www.ped-rheum.com/content/6/SI/P47

(C) 2008 Bracaglia et al; licensee BioMed Central Ltd.

\section{Background}

Uveitis occurs in 10\%-15\% of patients with JIA and is still one of the most frequent causes of acquired blindness in the developed world. Female sex, oligoarticular onset, serum antinuclear antibodies (ANA) and early onset of uveitis seem to increase the development of chronic uveitis. If topical treatment fails, second-line agents may be used, but not all patients respond. Infliximab has been reported to be effective in some of these cases. This study aims to assess the response and side effects associated with infliximab in JIA patients with uveitis

\section{Methods}

Fourteen patients, ( 3 male and 11 female) aged from 6 to 26 years, were treated with infliximab between January 2005 and April 2008. Mean age at the beginning of therapy was 9 years and 8 months.

All patients received also methotrexate $(15 \mathrm{mg} / \mathrm{mq}$ weekly). Infliximab was administered at $5 \mathrm{mg} / \mathrm{kg}$ dose at $0,2,4,6$ weeks and then every two months. Uveitis activity was evaluated as number of anterior chamber cells every month.

\section{Results}

Infliximab was well tolerated and no immediate adverse effects were recorded. Three patients achieved a complete remission of uveitis for more than one year and stopped anti-TNF treatment. Eight patients showed a good response with improvement of inflammatory ocular activity and decreased episodes of uveitis. Those patients are still on infliximab. Two patients were unresponsive to the drug after one year.

\section{Conclusion}

In our experience infliximab was effective in $85 \%$ of patients and none developed any serious systemic adverse events attributable to infliximab.

\section{References}

I. Foeldvari I, Nielsen S, Kümmerle-Deschner J, Espada G, Horneff G, Bica B, Olivieri AN, Wierk A, Saurenmann RK: Tumor necrosis factor-alpha blocker in treatment of juvenile idiopathic arthritis-associated uveitis refractory to second-line agents: results of a multinational survey. J Rheumatol 2007, 34(5): I I 46-50.

2. Tynjälä Pirjo, Lindahl Päivi, Honkanen Visa, Lahdenne Pekka, Kotaniemi Kaisu: Infliximab and etanercept in the treatment of chronic uveitis associated with refractory juvenile idiopathic arthritis. Ann Rheum Dis 2007, 66(4):548-50. 